\title{
Grey sex
}

\section{Susan Quilliam}

\section{Still going strong}

Life, the old saying goes, begins at forty. The concomitant cultural myth used to be that sex probably ends at around the same age. Certainly the majority of our grandparents' or even our parents' generation would have thought it unusual, if not a little distasteful, to be still going strong in that department much beyond mid-life. Menopause marked for her a welcome relief from continuous childbearing and therefore sex was off the agenda for him too.

2009, and it's all change. Two recent studies, by researchers at the Universities of Chicago and Gothenburg, respectively, suggest that the majority of us are now sexually active well into our sixties, and a quarter of us well into our eighties. Yes, there may be age-linked health problems - erectile dysfunction for him, postmenopausal dryness for her - but remove those and, given willing partners, desire is alive and well and celebrating its golden wedding.

\section{The majority of us are now sexually active well into our sixties, and a quarter of us well into our eighties.}

Which, of course, raises some interesting questions for those of us who are working in the sexual health field and who have, up to now, perhaps thought that our core market was the sexually-enthusiastic teenager and the conceptionmotivated thirty-something. We are not consciously focused on the sixty-plus market; furthermore, we may assume that when they appear in our consulting rooms, sex is the last thing on their minds. If we do assume that, we may well be mistaken.

\section{Being aware}

Hence the core aim of this article is simple: to raise awareness of the fact that those of pensionable age may well have sexual desires, hopes, concerns and aspirations, which we as health professionals need to acknowledge.

So an approach for vaginal lubricant shouldn't raise an eyebrow, a request for erection medication shouldn't merit a second glance, whatever the date on a patient's birth certificate. In fact, the response to the patient should not only be positive but could well be envious; many studies suggest that older folk are typically more sexually satisfied and fulfilled than their younger cohorts.

And we don't need to wait for the patient to make the first move. A diagnosis of diabetes, heart disease, rheumatoid arthritis or any condition that might impact on sexual pleasure should - when addressing a 60-year-old patient just as when addressing a 30-year-old - be accompanied by the same sort of guidance about how to offset that impact.

J Fam Plann Reprod Health Care 2009; 35(2): 123-124

\section{Cambridge, UK}

Susan Quilliam, BA, Cert Ed, MNLP, Freelance Writer, Broadcaster and Agony Aunt

Correspondence to: Ms Susan Quilliam.

E-mail: susan@susanquilliam.com

\section{Inhibition}

One might assume, of course, that such guidance need only be minimal. For the sixty-something patient isn't inexperienced, isn't emotionally immature; they can, joy of joys, be expected to take sex seriously, to not trivialise it or do it casually. It should be much easier to speak directly to the older patient, to discuss the issues clearly and then rely on them to take on board what is said.

\section{Many studies suggest that older folk are typically more sexually satisfied and fulfilled than their younger cohorts.}

And many do. But sadly - through no fault of their own - not all will. Even the sixty-something patient, let alone the seventy-something, was brought up in a very different, pre-sexual-liberation era - and crucially by pre-sexualliberation parents. Their childhood may well have been inhibited, their teen years a struggle to navigate society's constraint, their adult life marked by an inability to talk about sex - even if they are enjoying sex hugely.

And particularly if they are enjoying it hugely, and it is a crucial and intimate part of their lives, older patients may have a delicate sense of personal privacy that younger clients sometimes don't. Simply opening the discussion may well need tact, permission, above all normalisation: "I always ask my patients about their love life ... it's usual for people with your condition to have questions about sex".

\section{Lack of sex education}

Once discussion is opened, even the most open and uninhibited patient may also be relatively uninformed. Whether or not their family life provided good sex education, their school almost certainly won't have. Sex education in the mid-years of the last century was typically biological; it provided full coverage of the mating rituals of bunny rabbits, but little or no coverage of human physiology and none at all of human emotions. The patient who married in their early twenties and is now, 40 years on, struggling with a sexual issue, may have absolutely no accurate information to fall back on.

Worse, because they have been married for 40 years, they may feel embarrassed to seek out that knowledge. If they've had good, solid, loving sex for two-thirds of their lives; it can feel somehow shaming to themselves and disloyal to their partner to admit that they don't know what to do about age-linked lack of performance, lack of climax or lack of desire.

\section{Turning to a health professional for support is a sign of life effectiveness and emotional wisdom, not of some kind of failure or immaturity.}

It may help to tactfully point out that it is absolutely not their fault - or their problem - that for their cohort sex education was lacking. Turning to a health professional for support is a sign of life effectiveness and emotional wisdom, not of some kind of failure or immaturity. 


\section{Innocence}

One area here is particularly difficult. Recent studies suggest that the rate of sexually transmitted infections (STIs) among older age groups has rocketed in the last decade - more, that such groups are nearly half as likely as the younger age group to use a condom when having sex with a new partner for the first time.

The reasons for this reluctance are as yet not completely researched, but we can make an informed guess. For this older group, first-time sex is likely following a longish period of monogamous sex with a committed partner. For them, fidelity has been the norm for decades so they assume it's been the norm for any new partner they sleep with. But it may not have been for that new partner, even during their relationship - and since that relationship, they may well have been making up for lost time, without the benefit of protection.

\section{The older-age cohort may think that STIs have nothing to do with them.}

Plus - often because the media catastrophises the STI rate among teens and twenties - the older-age cohort may think that STIs have nothing to do with them. With even more ignorance than their own children have - and twice as much innocence - they may be caught rather than taught.

The best response from health professionals? First, an awareness that an older patient with relevant symptoms may be suffering from an STI, despite their advancing years. And second, an awareness that that patient - or anyone else asking for sexual support and advice - may need information and guidance about protection, together with a clear statement that while they have had no other partners in the last few decades, their future lovers may well have had, and there is no shame in that.

\section{Good news}

It may seem as if this article is all doom and gloom; I believe that the opposite is true. And here I have to come clean. The cohort I've been talking about in this article is my own; born in 1950, next year I will proudly become a senior citizen.

So I speak personally as well as professionally when I say that albeit the sixty-something age group may present challenges, it's wonderful that they (read 'we') are having sex. It's wonderful that perhaps for the first time in history - especially for women - passion after sixty is seen as not only possible, not only normal, but also natural. I am deeply grateful - as should we all be - that we no longer live in an era that puts any age limit on sexual pleasure, but encourages it as healthy and health-giving, both physically and emotionally. The ultimate message of this article is not doom and gloom but celebration.

And anticipation. As I pick up my bus pass next year, I fully intend to join the ranks of eroticised pensioners, and continue to hugely enjoy grey sex!

Statements on funding and competing interests Funding None identified. Competing interests None identified.

\section{JOURNAL REVIEWS}

Evidence that in healthy young women, a sixcycle treatment with oral contraceptive containing $30 \mathrm{mcg}$ of ethinylestradiol plus $2 \mathrm{mg}$ of chlormadinone acetate reduces fat mass. Uras R, Orrù M, Etzi R, Peppi G, Marotto MF, Pilloni M, et al. Contraception 2009; 79: 117-121

Weight gain is a commonly reported side effect of hormonal contraception. In this paper, the authors present data to suggest that six cycles of combined oral contraception containing $30 \quad \mu \mathrm{g}$ ethinylestradiol and $2 \mathrm{mg}$ chlormadinone, an antiandrogenic synthetic progesterone derivative, alters body composition - specifically, that it lowers fat mass - when compared with no contraception.

Forty-eight healthy women, of normal body mass index (BMI) and regular cycles, attending for contraceptive advice were recruited. Those requesting hormonal contraception $(n=24)$ were given a six-cycle course of the above preparation; those using natural methods of contraception ( $n=24)$ were recruited to the control group. At each visit, anthropometric measurements were made and multifrequency bioimpedance analysis was used to calculate total body water, extracellular and intracellular body water, fat mass and fat-free mass. Subjects were measured at recruitment, and after the third and sixth cycles; the treatment group were measured on Days 15-18 of their cycle, whereas controls were measured in the follicular phase of their menstrual cycle. No blinding measures are reported.

No significant between-group difference in the above parameters was reported at the point of recruitment ( $p$ values not published), nor did there appear to be any longitudinal betweengroup changes. However, a reduction in fat mass was demonstrated in the treatment group with a
$10 \%$ reduction from baseline at the third visit, which was statistically significant $(p<0.05)$, compared with no significant change in the control group.

These findings are of potential clinica interest; $\mathrm{BMI}$ is a factor when prescribing oral contraception, and possible weight gain can be a consideration for patient acceptability. These data seem to suggest that not only does this particular preparation of contraception not lead to weight gain, but that there is active reduction in fat mass. However, in this study, limited numbers and potential introduction of bias from factors such as timing of measurements or lack of researcher blinding necessitate further study before clinical practice is altered.

Reviewed by Sarah Barr, BSc, MBChB Tommy's Clinical Research Fellow, Simpson Centre for Reproductive Health, Edinburgh, UK

The risk of venous thromboembolism associated with the use of tranexamic acid and other drugs used to treat menorrhagia: a case-control study using the General Practice Research Database. Sundström A, Seaman H, Kieler H, Alfredsson L. Br J Obstet Gynaecol 2009; 116: 91-97

Approximately $30 \%$ of women complain of menorrhagia and tranexamic acid has been used since 1966 for its treatment, as it blocks the activation of plasminogen and therefore prevents the decomposition of fibrin in clotted blood. Due to this mechanism of action, it has been suspected that tranexamic acid might increase the risk of thrombosis. A recent Cochrane Review was unable to comment on the risk of thromboembolic events with antifibrinolytics, although it did note that long-term studies in Sweden have found that the rate of incidence of thrombosis in women treated with tranexamic acid is similar to the spontaneous frequency.

To further investigate the possible link between venous thromboembolism (VTE) and tranexamic acid, the authors of this case-control study used data from the UK General Practice Research Database to examine whether women aged 15-49 years with a diagnosis of menorrhagia had higher rates of incidence of VTE if they had been exposed to tranexamic acid and other drugs used to treat menorrhagia, compared to matched controls.

Although the authors report finding an association between the use of tranexamic acid and VTE from the study data, this was not statistically significant [adjusted odds ratio (OR) $3.20 ; 95 \%$ confidence interval (CI) 0.65-15.78]. The authors acknowledge that the study was underpowered and only had a $45 \%$ power to detect an odds ratio of 3 . The paper also reports finding an association between the use of mefenamic acid (adjusted OR 5.54; 95\% CI 2.13-14.40) or norethisterone (adjusted OR 2.41; 95\% CI 1.00-5.78) and VTE, however this was not the primary objective of the study and the confidence intervals are again wide.

The authors found that a diagnosis of anaemia or a low haemoglobin - taken as a proxy for more severe menorrhagia - was associated with an increased risk of VTE (adjusted OR 2.23; 95\% CI 1.02-4.86), and suggest the possibility that menorrhagia itself could be a prothrombotic condition.

Reviewed by Bruno Rushforth, MBChB, DFSRH General Practice Specialty Registrar, Outwood Park Medical Centre, Wakefield, UK 